\title{
Characteristics of ornamental fish enterprise in Ratnagiri District in Maharashtra State, India
}

\author{
H. R. BHATKAR, B. M. YADAV*, M. M. SHIRDHANKAR, K. J. CHAUDHARI, \\ S. M. WASAVE* AND S. V. PATIL \\ College of Fisheries (Dr. B. S. Konkan Krishi Vidyapeeth), Ratnagiri - 415 712, Maharashtra, India \\ *ICAR-Central Institute of Fisheries Education, Seven Bunglow, Versova, Mumbai - 400 061, Maharashtra, India \\ e-mail: cpbharat@gmail.com
}

\begin{abstract}
The present study was carried out to document the characteristics and to analyse the present status of ornamental fish enterprise in the Ratnagiri District of Maharashtra State. A total of 71 ornamental fish enterprises were surveyed. Ornamental fish industry of Ratnagiri District was dominated by men and majority of them belong to one religion. The ornamental fish enterprises was found to be the primary source of livelihood for these people. Maximum units were established in less than 0.01 ha land. The retail shops were small with an area of 10-20 sq. $\mathrm{m}$. The major items of non-recurring expenditure were tanks, water supply and electrical items, water treatment equipments, building for housing the tanks, water quality parameter analysis equipments, aerators, blowers and hosing for aquarium tanks. Major items of recurring expenditure were dry feed, electricity charges and communication charges. Goldfish and angelfish were the most preferred groups due to the demand in market. Monsoon crops were mostly taken by ornamental breeding and rearing units. Dry feed was commonly used by the enterprise for feeding and salt as chemical for treating fish while oxytetracycline was the common antibiotic used by ornamental fish entrepreneurs. The maximum breeding and rearing unit holders were those who got trained as beneficiaries of the Rainbow Revolution Scheme (RRS) of the Marine Products Export Development Authority (MPEDA).
\end{abstract}

Keywords: Characteristics, Enterprise, Ornamental fish, Ratnagiri

\section{Introduction}

Ornamental fishes are referred to as the jewels of aquatic body for their shape, tiny size and bright colour (Banerjee, 2009). Ornamental fish are today the world's most popular pets and fish keeping is the second most popular hobby after photography (Singh and Dey, 2003). The global ornamental fish trade in retail level is worth more than US\$ 8 billion with an average annual growth of $9 \%$, while the entire industry including plants, accessories, aquarium, feed and medications is estimated to be worth more than US\$18-20 billion (Sailas, 2011). Availability of skilled manpower, well established communication network, international airports and export promotion zone (EPZ) in the country, provides vast scope for the promotion of ornamental fish trade and export. There is vast opportunity for growth of ornamental fish enterprise in the domestic trade which is reported to grow at $20 \%$ annually (Sailas, 2011). Among ornamental fishes, goldfish (Carrassius auratus) is the most admired ornamental fish throughout the world and also in India (Gupta and Banerjee, 2008). With advances in breeding, transport and recent developments in aquarium technology, more and more species are being added in the list of fish traded.
In Maharashtra, the ornamental fish breeding and trade is mainly concentrated in Mumbai city because of the airport facility and local demand in the metro city. The districts like Ratnagiri and Sindhudurg in south Konkan area have huge advantage due to proximity to the Western Ghats and suitable climatic conditions. Therefore, Marine Products Export Development Authority (MPEDA) has chosen Maharashtra as one of the states for the Rainbow Revolution Scheme (RRS).

The Government of India has identified ornamental fish sector as one of the thrust areas for generating employment opportunities and augmenting the foreign exchange earnings and has launched various schemes for the development of export oriented ornamental fish industry in India (Sailas, 2011). The MPEDA, with the mandate to encourage the breeding and export of fish from India, has named this innovative endeavour as 'Rainbow Revolution'. Along with MPEDA, National Fisheries Development Board (NFDB) is the agency working for development of ornamental fish enterprise.

Ratnagiri District $\left(16^{0} 31^{\prime} \mathrm{N} 73^{\circ} 02^{\prime} \mathrm{E} ; 18^{\circ} 04^{\prime} \mathrm{N} 73^{\circ}\right.$ $52^{\prime}$ E) situated along the western coast of the Konkan 
region, between the Western Ghats and the Arabian Sea in Maharashtra State has conducive environmental conditions for culture of various ornamental fishes and also has wide ornamental fish market. The present study provides insight on the status of ornamental fish industry in the Ratnagiri District which will be helpful for formulating policies for the development of the ornamental fish sector.

\section{Materials and methods}

Study area

The Rainbow Revolution Scheme(RRS) implemented by the MPEDA played a key role in establishment of ornamental fish enterprise in Ratnagiri District (Fig. 1).

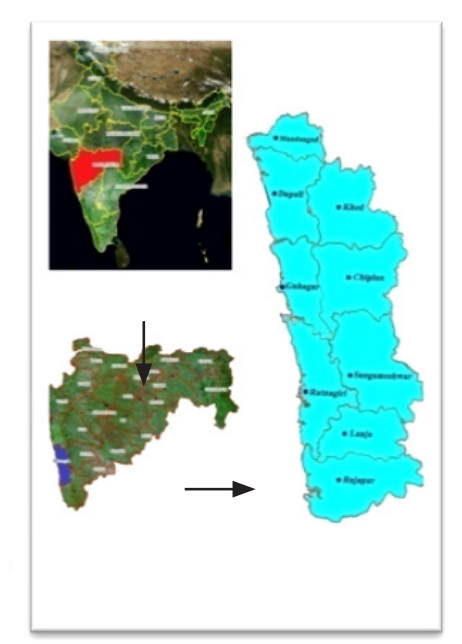

Fig. 1. The study area along with all the blocks of Ratnagiri District, Maharashtra

Sample size and sampling procedure

Altogether 71 entrepreneurs were interviewed. The data required for this purpose was collected in two stages. In the first stage, general information was collected and it was followed by collection of data related to characteristics of ornamental fish enterprise.

Interview schedule: The primary data were collected through surveys using semi-structured interview schedules on various aspects especially with respect to the breeders, rearers and retailers (McGoodwin, 2001).

Demographic features of ornamental fish entrepreneurs: Information regarding demographic features of ornamental fish entrepreneurs such as gender, religion, education, occupation and ownership of enterprises was recorded.

Characteristic of ornamental fish enterprise: Information regarding dimension of ornamental fish units, proportion of glass and cement tanks, recurring expenditure, fish varieties, reasons for preference of fish, use of chemicals, probiotics, medicines and accessories were recorded. Details on types of feed and training undergone by entrepreneurs were also collected. Seasonal variations in fish holdings along with fish variety according to season were documented, with their percentage value ranked from highest to lowest.

\section{Statistical analysis}

The appropriate statistical tools were employed wherever required (Snedecor and Cochran, 1967). The frequency distribution method along with percentage analysis technique was the key statistical technique used. The nonparametric test such as $\chi^{2}$ (Chi-Square) test and Sign test were employed to test the significant difference (Zar, 2005).

\section{Results and discussion}

\section{Demographic features of ornamental fish entrepreneurs}

Gender: During the present study, it was observed that male ornamental fish entrepreneurs $(88.73 \%)$ were significantly higher $(\mathrm{p}<0.05)$ than female entrepreneurs. Previously, gender analysis of ornamental fish entrepreneurs from Cuddalore District also revealed similar situtation (Selvarasu and Sankaran (2011). Ornamental fish enterprise is a full time job that requires hard work and therefore, sparing that much time may be a difficult task for housewives. This may be one of the reasons for the dominance of 'males' among ornamental fish entrepreneurship during the present study.

Religion: Amongst the ornamental fish entrepreneurs from Ratnagiri District, significant $(\mathrm{p}<0.05)$ dominance of people from one particular religion (94.37\%) was documented compared to other religions. The primary business of maximum people from the latter religion in Ratnagiri District was catching of marine food fishes and related activities. This could be the reason for involvement of more number of people from former religion in ornamental fish culture.

Education: It was observed that maximum percent of ornamental fish entrepreneurs (32.39\%) was educated up to senior secondary class (SSC) (Fig. 2). Previously, analysis of educational background of ornamental fish entrepreneursrevealed that maximum entrepreneurs were educated up to undergraduate level (Selvarasu and Sankaran, 2011). It is concluded that the entrepreneurs with SSC qualification may be earning more money from this enterprise than they would have earned from other business. Lower educational level recorded during the present study may be a factor responsible for undertaking the ornamental fish enterprise.

Occupation status: The present study revealed that majority (90.14\%) of ornamental fish entrepreneurs were undertaking this entrepreneurship as primary occupation. 


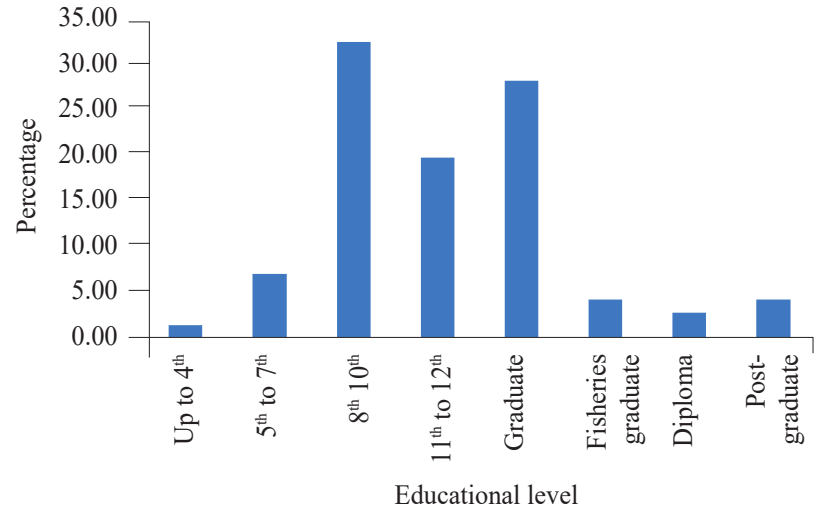

Fig. 2. Classification of ornamental entrepreneurs according to education level

Ownership: Ownership of enterprise plays a major role for increasing profit. Most of the ornamental fish entrepreneurs $(87.30 \%)$ were found to be operating their own unit, followed by entrepreneurs who operated on lease and rental basis. Initial capital investment was comparatively less and affordable to a new entrant with back up of RRS which offered $50 \%$ subsidy for the entire unit. Therefore, most of the units observed were own establishments rather than leased units.

\section{Characteristics of ornamental fish enterprise}

Dimensions of units: In the present study, ornamental fish units were categorised on the basis of the area occupied by the unit (Fig. 3). Maximum number of breeding and rearing units $(61.70 \%)$ were established in $\leq 0.01$ ha area. The minimum land required construction as per RRS is 0.01 ha. A cluster of 30 units in Ratnagiri District developed under Jagannath

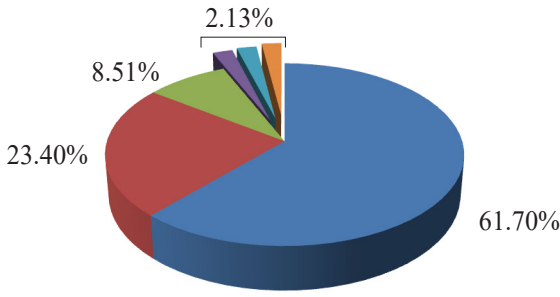

$\square<0.01 \mathrm{ha}, \approx 0.01-0.02 \mathrm{ha}, \approx 0.02-0.03 \mathrm{ha}, \approx 0.03-0.04 \mathrm{ha}$, - 0.04-0.05 ha, $>0.05$ ha

Fig. 3. Classification of ornamental fish breeding and rearing units according to dimension

Foundation, Lanja was established during 2008-2010 which also availed MPEDA subsidy and had established units as per the guidelines of RRS. Maximum percentage $(50 \%)$ of retail shops of Ratnagiri District established their units covering an area up to 10 to 20 sq. $\mathrm{m}$.

Assets availability: In the present study, it was observed that more than $90 \%$ of the ornamental fish breeding and rearing units possessed assets like cement and glass tanks, electric water pumps, pipeline, electrification, lights and their fixtures, power filters, aerators, water heaters, cemented brick wall structure, shade nets as well as hand nets (Fig. 4). Most of the enterprises have availed the subsidy from MPEDA and established the units as per guidelines of RS. Similarly, same percentage of fish retailers possessed glass tanks, electrification, lights and their fixtures, sponge filters, water heaters, racks and hand nets (Table 1).

Dimension of glass tanks: Glass tanks in ornamental fish units were classified on the basis of various dimensions. Maximum

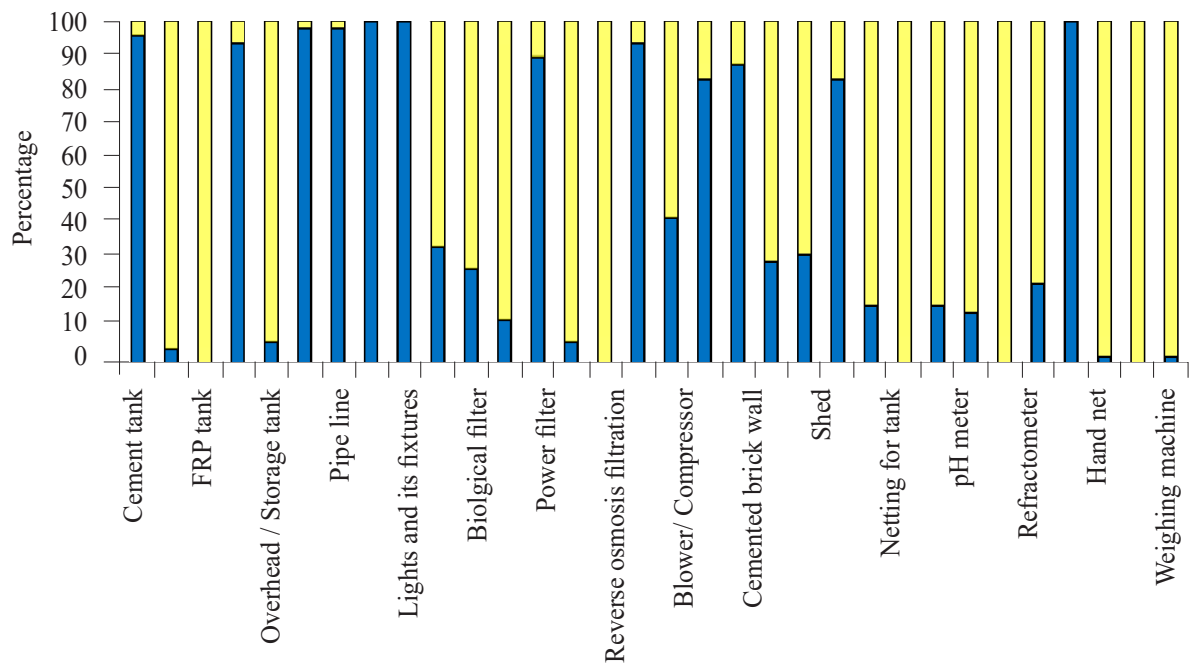

Facilities available

- Percentage (Yes), Percentage (No)

Fig. 4. Facilities available at ornamental fish breeding and rearing units 
Table 1. Facilities available at ornamental fish retail units

\begin{tabular}{|c|c|c|c|}
\hline Facilities & No. of entrepreneurs & Percentage & Significance \\
\hline \multicolumn{4}{|l|}{ Tanks } \\
\hline Glass tank & 24 & 100.00 & $\mathrm{p}<0.05$ \\
\hline Overhead tank & 0 & 0.00 & NT \\
\hline \multicolumn{4}{|l|}{ Water supply items } \\
\hline Electric water pump & 12 & 50.00 & $\mathrm{p}<0.05$ \\
\hline Pipe line & 14 & 58.33 & $\mathrm{p}<0.05$ \\
\hline \multicolumn{4}{|l|}{ Electrical items } \\
\hline Electrification & 24 & 100.00 & $\mathrm{p}<0.05$ \\
\hline Lights and its fixtures & 24 & 100.00 & $\mathrm{p}<0.05$ \\
\hline Generator/Inverter & 9 & 37.50 & $\mathrm{p}<0.05$ \\
\hline \multicolumn{4}{|c|}{ Water treatment equipments } \\
\hline Biological filter & 2 & 8.33 & $\mathrm{p}>0.05$ \\
\hline Sponge filter & 18 & 75.00 & $\mathrm{p}<0.05$ \\
\hline Power filter & 11 & 45.83 & $\mathrm{p}<0.05$ \\
\hline Ozoniser & 1 & 4.17 & $\mathrm{p}>0.05$ \\
\hline \multicolumn{4}{|l|}{ Life saving equipments } \\
\hline Aerator & 14 & 58.33 & $\mathrm{p}<0.05$ \\
\hline Blower & 9 & 37.50 & $\mathrm{p}<0.05$ \\
\hline Oxygen cylinder & 9 & 37.50 & $\mathrm{p}<0.05$ \\
\hline Water heater & 20 & 83.33 & $\mathrm{p}<0.05$ \\
\hline \multicolumn{4}{|c|}{ Water parameter analysis equipments } \\
\hline Dissolved oxygen meter & 0 & 0.00 & NT \\
\hline $\mathrm{pH}$ meter & 1 & 4.17 & $\mathrm{p}>0.05$ \\
\hline Thermometer & 7 & 29.17 & $\mathrm{p}>0.05$ \\
\hline Refractometer & 0 & 0.00 & NT \\
\hline \multicolumn{4}{|l|}{ Tank housing } \\
\hline Rack & 24 & 100.00 & $\mathrm{p}<0.05$ \\
\hline \multicolumn{4}{|l|}{ Other facilities } \\
\hline Hand net & 24 & 100.00 & $\mathrm{p}<0.05$ \\
\hline Packaging machine & 0 & 0.00 & NT \\
\hline Weighing machine & 0 & 0.00 & NT \\
\hline Feeding trays & 0 & 0.00 & NT \\
\hline Toys & 24 & 100.00 & $\mathrm{p}<0.05$ \\
\hline Microscope & 0 & 0.00 & NT \\
\hline
\end{tabular}

NT - Not tested for checking the significance

number of breeding and rearing units (72.34\%) possessed glass tanks in the category of 200 to 3001 capacity, while all the retail shops possessed glass tanks with maximum of 1001 capacity. The glass tanks were fabricated by most of the entrepreneurs as per the MPEDA guidelines for availing subsidy. The grade I units were approved by MPEDA for a cluster of 10 farmers within $5 \mathrm{~km}$ periphery. These 10 farmers developed the farms with identical assets and subsequently another group of farmers developed their units with similar structure. This may be the reason for similarity recorded with respect to tank sizes during the present study. It was also observed that goldfish and angelfish were dominant ornamental species reared. In an earlier study, Ream (2012) reported that goldfish requires 190 to 2201 tank for rearing and similarly, Twigg (2002) also reported that angelfish are reared in 1901 capacity water tanks. This may be the reason for the use of 200-300 1 capacity tanks by most of enterprises as recorded during the present study.

Dimension of cement tank: In the present study, it was observed that maximum number of breeding and rearing 
units $(63.83 \%)$ possessed tanks with 4000 to 60001 capacity. The cluster of 30 entrepreneurs working under Jagannath Foundation, Lanja had constructed cement tanks of similar size as per the MPEDA guidelines and also availed subsidy from MPEDA. Similarly, Ghosh et al. (2003) reported that most of the farmers used cement tank of 4000-6000 1 capacity in West Bengal for rearing units of ornamental fish.

Recurring expenditure: In the present study all the entrepreneurs were spending recurring amount per month on dry feed, electricity charge, communication charges and rubber bands. Expenditure towards purchase of fish per month was $83.10 \%$. Almost $50.7 \%$ of entrepreneurs were spending monthly recurring amount on chemicals, probiotics and medicine as well as water charges. These items seem to be common expenditure essential for operation of the enterprise.

Fish variety: From Fig. 5, it can be observed that goldfish and angelfish were the common fish varieties kept by almost $90 \%$ of the ornamental fish breeding and rearing units. Goldfish required water temperature up to $18-22^{\circ} \mathrm{C}$ whicle angelfish required $22-28^{\circ} \mathrm{C}$ temperature for better growth (Anon., 2004a, b). The environmental conditions in Ratnagiri District showed similar temperature range and therefore, most of the entrepreneurs kept these varieties because no extra effort needed for maintaining the temperature. Similar observations were also made by De and Ramchandra (2011) who reported that the major fish varieties traded in the domestic market were goldfish and angelfish. Similarly, Gupta and Benerjee (2008) also reported that goldfish contributed to over $50 \%$ of ornamental fish in the market. Ghosh et al. (2003) reported that the preferred egg laying varieties in West Bengal market were goldfish and angelfish.

Reason for preference of fish: All the ornamental fish entrepreneurs expressed high demand among customers as

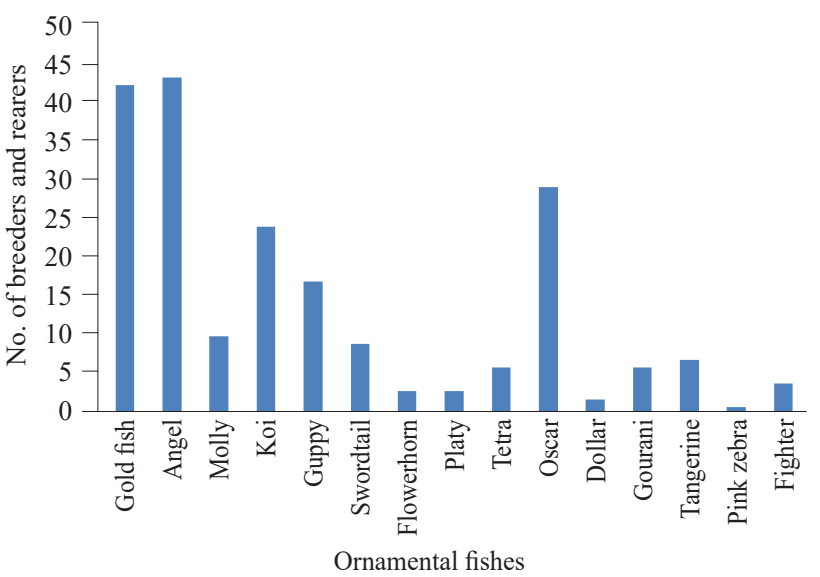

Fig. 5. Classification of ornamental fish breeding and rearing units according to fish species the major reason for preference for fish varieties kept in their units. Goldfish and angelfish were the fish varieties kept by most of the entrepreneurs as observed by Nath et al. (2010). These varieties can be easily maintained by hobbyists and are attractive as well as sturdy to maintain with minimum effort, which could be the reasons for high demand of these fish varieties.

Seasonal variation in fish holdings: From Fig. 6, it is obvious that, maximum percentage of ornamental fish entrepreneurs stocked fishes during monsoon season, followed by summer and winter seasons. Most of the entrepreneurs kept egg layers like angelfish and goldfish as main species and other fish varieties included live bearers like molly, guppy, swordtail and platy. Egg layers require water temperature in the range $18-28^{\circ} \mathrm{C}$ while for live bearers $21-28^{\circ} \mathrm{C}$ is the ideal range (Anon., 2004c, d). It was found that the temperature during monsoon season in Ratnagiri District falls in similar range which may be the reason for more number of entrepreneurs possessing these species during monsoon season. Nath et al. (2010) also reported that most of the species breed during monsoon season.

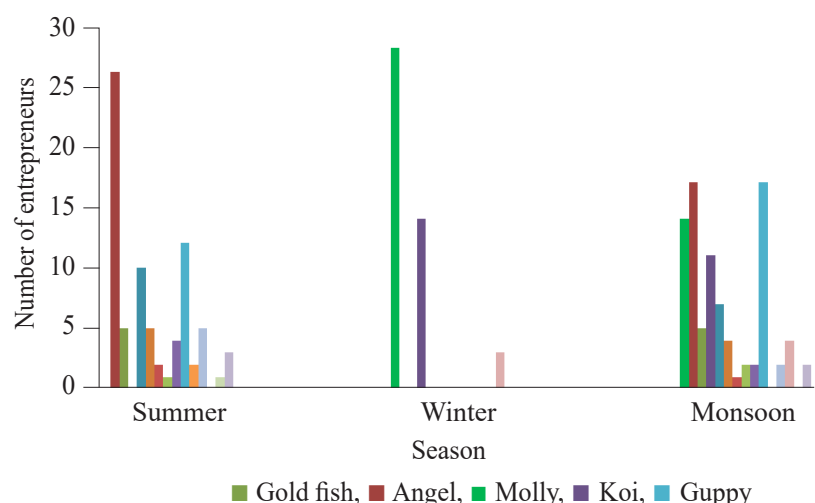

Fig. 6. Seasonal variation in species-wise stocking of fish in ornamental fish entrprise

Type of feed: It was observed that maximum number of ornamental fish entrepreneurs (78.87\%) used dry feed. However, a few of them used both dry and live food for their enterprise. Feed is one of the important and essential inputs in ornamental fish enterprise. The dry feeds used by ornamental fish entrepreneurs was mainly shrimp feed, whereas, live feed comprised mosquito larvae and moina. Unavailability of live feed in sufficient quantity may be the reason for limited use of live food. Some of the units used live feed collected from natural sources. Singh and Syed (2005) reported that ornamental fish trade is largely dependent on live feed as well as artificial feed. Nath et al. (2010) observed that ornamental fish farmers used zooplankton (Daphnia) in dry and live 
condition. Ghosh et al. (2003) reported that small scale ornamental fish farmers of West Bengal used low cost live feed like green water, water fleas, tubifex or sludge worm, mosquito larvae and chopped earth worms.

Chemical, probiotics and medicines: It was recorded that all the ornamental fish entrepreneurs used salt as a chemical and oxytetracycline, methylene blue, vitamins, potassium permanganate and formalin as common medicines. In ornamental fish farming, proper water quality maintenance was the primary preventive measure against diseases. Salt was used for treatment of fish as it is available easily at cheaper price in open market in comparison to other chemicals and medicines. Similar to our observations, Ghosh et al. (2003) reported that ornamental fish farmers of West Bengal used easily available chemicals and medicines (common salt, methylene blue, copper sulphate and potassium permanganate) for treating diseases. Selvarasu and Sankaran (2011) reported that more than $17 \%$ of aquarists used salt.

Accessories and equipment sale at retail shops: Almost 90\% of ornamental fish retailers sold tanks, gravel, artificial plants, background posters, toys, tank roofs, filters, feed, chemicals and hand nets which are common accessories required to set up a home aquarium.

Trained manpower in enterprise: In the present study, it was observed that majority of the ornamental fish entrepreneurs $(80.28 \%)$ attended training programmes. Training programmes help to improve skills and knowledge of entrepreneurs and is beneficial for increasing profit of the enterprise. Most of the entrepreneurs of Ratnagiri District have availed the subsidy from MPEDA under the RRS and it was mandatory for the beneficiary to undergo training programme before starting the unit. Earlier, Selvarasu and Sankaran (2011) also reported that more than $12 \%$ of the respondents established enterprise after attending training programme.

The status of ornamental fish farmers and entrepreneurs in Ratnagiri District of Maharashtra was documented for the first time during the present study. Demographic features and characteristics of the ornamental fish entreprises recorded during the study will be helpful in planning and executing development programmes for the ornamental fish trade in Maharashtra. Also the data will be helpful in monitoring and evaluating the Rainbow Revolution Scheme implemented by MPEDA for the development of ornamental fish trade in the country.

\section{Acknowledgements}

Authors would like to thank Dr. Tapas Bhattacharya, Vice-Chancellor, Dr. Balasaheb Sawant Konkan Krishi Vidyapeeth, Dapoli and Dr. R. Pai, Associate Dean, College of Fisheries, Ratnagiri for providing all support.
Thanks are due to all ornamental fish producers who provided information for the study.

\section{References}

Anon. 2004a. Goldfish (Carassius auratus) care sheet. http://www. petco.com/caresheets/fish/Goldfish.pdf. PETCO Animal Supplies (Accessed 7 May 2013).

Anon.2004b.Angelfish(Pterophyllumscalare) caresheet. http://www. petco.com/caresheets/fish/Angelfish.pdf. PETCO Animal Supplies (Accessed 7 May 2013).

Anon. 2004c. Freshwater egglayers care sheet. http://www.petco. com/caresheets/fish/egglayers.pdf. PETCO Animal Supplies (Accessed 7 May 2013).

Anon. 2004d. Freshwater livebearers care sheet. http://www. petco.com/caresheets/fish/Livebearers.pdf. PETCO Animal Supplies (Accessed 7 May 2013).

Banerjee, S. D. 2009. Scenario of ornamental fish and fisheries in West Bengal. MPEDA Newsletter, p. 30-31.

De, S. S. and Ramachandran, A. 2011. Marketing channels in ornamental fish trade in West Bengal. Fish. Technol., 48(2): 163-170.

Ghosh, A., Mahapatra, B. K. and Datta, N. C. 2003. Ornamental fish farming - Successful small scale aqua business in India. Aquac. Asia, 8(3): 14-16.

Gupta, S. and Benrjee, S. 2008. Ornamental fish trade in West Bengal. Fishing Chimes, 28(8): 25-26.

McGoodwin, J. R. 2001. Understanding the culture of fishing communities: A key to fisheries management and food security. FAO Fisheries Technical Paper No. 401. Food and Agricultural Organisation, Rome, Italy, 287 pp.

Nath, A. K., Roy, S. and Paul, A. 2010. Ornamental fish trade - with focus on Howrah market, West Bengal, India. Fishing Chimes, 30(7): 24-28.

Ream, S. 2012. The golden rules - Goldfish guide. www.Petfish.Net/ $\mathrm{kb} / \mathrm{entry} / 104$ (Accessed 7 May 2013)

Silas, E. G., Gopalakrishnan, A., Ramachandran, A., Anna Mercy, T. V., Kripan Sarkar, Pushpangadan, K. R., Anil Kumar, P., Ram Mohan, M. K. and Anikuttan, K. K. 2011. Guidelines for green certification of freshwater ornamental fish. The Marine Products Export Development Authority, Kochi, India. xii + $106 \mathrm{pp}$.

Selvarasu, A. and Sankaran, A. 2011. Marketing strategies vis-a-vis consumer preference for aquarium business service. Int. $J$. Latest Trends Ecol. Sci., 1(1): 31-46.

Singh, T. and Dey, V. K. 2003. Ornamental fish trade runs into billions. INFOFISH Int., 5: 55-60.

Singh, A. K. and Syed, H. A. 2005. Ornamental fish culture in Bihar. prospects as a cottage industry. Fishing Chimes, 25(6): 9-18.

Snedecor, G. W. and Cochran, W. G. 1967. Statistical methods, $6^{\text {th }}$ edn. Oxford and IBH Publishing Co., New Delhi, $593 \mathrm{pp}$. 
Twigg, M. 2002. Breeding angelfish. http://www.angelsplus.com/ ArticleBreeding.htm (Accessed 7 May 2013)
Zar, J. H. 2005. Biostatistical analysis, $4^{\text {th }}$ edn. Pearson Education Pvt. Ltd., Singapore, 663 pp.

Date of Receipt : : 27.01.2017

Date of Acceptance : $\quad 30.03 .2017$ 